\title{
Survey of the long term incidence of osteonecrosis of the hip and adverse medical events in rheumatoid arthritis after high dose intravenous methylprednisolone
}

I A WILLIAMS ${ }_{1}^{1}$ A D MITCHELL ${ }^{2}$ W ROTHMAN $^{1}$ P TALLETT, $\frac{\dot{\omega}}{\omega}$ K WILLIAMS ${ }^{1}$ AND P PITT ${ }^{1}$

From the ${ }^{1}$ Departments of Rheumatology and Radiology, Kent and Sussex Hospital, Tunbridge Wells, Kent, and the ${ }^{2}$ Medical Department, Upjohn Ltd

SUMmARY A prospective, randomised, double blind, matched cohort survey using retrospective data was undertaken to assess the long term incidence of osteonecrosis of the hip and adverse ${ }^{\circ}$ medical effects occurring after intravenous pulsed methylprednisolone used in the treatment of rheumatoid arthritis over the period 1977-86. One hundred and forty three patients were matched for age, sex, duration and severity of the disease, erosive and serological status $\frac{\Phi}{3}$ Information was obtained by direct questioning and from hip $x$ rays, the latter being reacp independently by two 'blind' radiologists. Two definite cases of osteonecrosis were identified, one in both the treated and control groups and three possible cases (radiological disagreement) $0^{\circ} 0^{\circ}$ the treated group. Adverse medical events, when analysed by systems, were similar in bogh groups. This study did not provide evidence of increased osteonecrosis of the hip or adverseo medical events in the treated group compared with the control group.

Key words: corticosteroid 'pulse therapy'—complications, long term.

For many years intravenous methylprednisolone (IVMP) has been employed with benefit as a therapeutic agent in renal transplantation and for over a decade in connective tissue diseases such as systemic lupus erythematosus and more recently rheumatoid arthritis (RA). ${ }^{1-9}$ The adverse effects of IVMP occurring at the time of administration or within a few days are well documented. These include sudden death ${ }^{10-12}$ and death due to infections, ${ }^{13}{ }^{14}$ hypersensitivity, ${ }^{15}$ and a variety of complications varying in incidence and severity. ${ }^{16-19}$ This variety of effects almost certainly reflects the severity and type of disease being treated, the dose regimen, and degree of monitoring. Although osteonecrosis is recognised as a late complication following renal transplantation, it is uncertain whether the incidence is higher with IVMP than with an oral glucocorticoid preparation. ${ }^{20-22}$ There

Accepted for publication 18 March 1988.

Correspondence to Dr I A Williams, Department of Rheumatology, Kent and Sussex Hospital, Tunbridge Wells, Kent TN4 8AT. is no definite information about the long term incidence of osteonecrosis or adverse medical effectso. after the use of IVMP in RA.

To assess these effects we undertook a prospective, randomised, double blind, matched cohort $\frac{}{3}$ survey using retrospective data obtained from the records of all patients with RA who had beeno treated in one rheumatology department. Over one fifth of these patients had been treated with IVMP음 within the previous eight to nine years $(1977-86)$. $\frac{D}{2}$

\section{Patients and methods}

The records of approximately 8000 patients who were, or had been, under the care of one consultant $\omega$ (IAW) were considered. All cases of probable oro definite rheumatoid arthritis (American Rheumaro tism Association criteria) were extracted (639); those who had received IVMP (143) were removed? to form the treatment group.

A computer program (db111 using a PC IBM) was: then run to select randomly optimally matched pairs 
not treated with IVMP. The data used were sex, date of birth, date of onset of RA, serology, erosive changes, and disease severity. Severity (mild, moderate, or severe) was assessed by one investigator (IAW) on the basis of the most recent clinical information available.

Most patients were matched on the first two passes, but a third pass was required to complete the matching. Although they were not matched for drug treatment, no patient in the treatment group was receiving corticosteroids at the time of their first infusion.

The date that treated patients first received an infusion was entered into the database and used as the reference date for the untreated matched patient in each pair. Thus a subpopulation cohort of 286 patients was identified for a prospective assessment of outcome on retrospective data. An interview listing was generated sorted on hospital number providing names, address, telephone number, and reference date. With the knowledge of the reference date for each patient a 'blinded' non-medical interviewer attempted to contact all the patients listed either by personal contact or telephone. With the help of guidance notes specific questions were asked concerning (a) significant hip problems before or after the reference date. Because most patients were anatomically imprecise pain or discomfort in the region of the groin, upper thigh, or buttock was accepted as arising from the hip. (b) The occurrence of any significant medical event (medical, surgical, obstetric, etc) where a definite diagnosis had been made subsequent to the reference date. The medical events recorded were then classified into system groups by one investigator (ADM), who had no clinical involvement with any of the patients studied. An attempt was made to $x$ ray the hips of all patients treated with IVMP, but in the control group only those who had reported increasing problems with their hips after the reference date. Although this may have 'favoured' the control group, it was considered unethical to $x$ ray control patients without good clinical reason. All $x$ rays were read separately by two blinded consultant radiologists, who were asked to identify any cases of osteonecrosis. Before the study an arbitary decision was taken to record a positive result whether both or one radiologist reported osteonecrosis.

Fisher's exact test was applied to the data obtained from the blind reading of the hip $x$ rays.

\section{Results}

Table 1 shows that the computer matching of treated and control groups was remarkably accurate.

Six hundred and thirty nine patients with RA (460 female, 179 male) were identified. Of these, $143 \mathrm{had}$ received a total of 309 IVMP infusions over a period of eight to nine years between 1977 and 1986. Tables 2 and 3 show the distribution of IVMP infusions.

Table 1 Characteristics of matched pairs

\begin{tabular}{|c|c|c|}
\hline & \multicolumn{2}{|l|}{ Patients } \\
\hline & $I V M P$ & Control \\
\hline Men (n) & 41 & 41 \\
\hline Women (n) & 102 & 102 \\
\hline Mean age in years* (range) & $52 \cdot 1(22-79)$ & $52.4(19-77)$ \\
\hline \multicolumn{3}{|l|}{ Serology } \\
\hline Positive & 106 & 106 \\
\hline Negative & 35 & 32 \\
\hline Unknown & 2 & 5 \\
\hline \multicolumn{3}{|l|}{ Erosions } \\
\hline Positive & 98 & 100 \\
\hline Negative & 42 & 41 \\
\hline Unknown & 3 & 2 \\
\hline \multicolumn{3}{|l|}{ Severity } \\
\hline Mild & 54 & 54 \\
\hline Moderate & 63 & 63 \\
\hline Severe & 25 & 26 \\
\hline Unknown & 1 & 0 \\
\hline \multicolumn{3}{|l|}{ Mean follow up in } \\
\hline \multicolumn{3}{|l|}{ Duration of RA } \\
\hline $0-10$ years & 92 & 78 \\
\hline $10-20$ years & 43 & 58 \\
\hline $20-30$ years & 7 & 5 \\
\hline $30+$ years & 1 & 2 \\
\hline
\end{tabular}

${ }^{*}$ At the time of first IVMP reference date.

†From the first infusion reference date.

Table 2 Distribution of IVMP infusions

\begin{tabular}{lc}
\hline Unit dose & \\
\hline Grams & Number \\
\hline $0 \cdot 5$ & 39 \\
$1 \cdot 0$ & 256 \\
$2 \cdot 0$ & 13 \\
$3 \cdot 0$ & 1 \\
\hline
\end{tabular}

Table 3 Distribution of infusion/patients

\begin{tabular}{ll}
\hline $\begin{array}{l}\text { Number of separate } 1 \mathrm{~g} \\
\text { infusions }\end{array}$ & $\begin{array}{l}\text { Number of treated } \\
\text { patients }\end{array}$ \\
\hline 1 & 70 \\
2 & 35 \\
3 & 15 \\
4 & 10 \\
5 & 5 \\
6 & 4 \\
7 & 2 \\
10 & 1 \\
11 & 1 \\
\hline
\end{tabular}


Of the 143 patients treated with IVMP, five had died, eight were uncontactable, and thus 130 interviewed. Tables 4 and 5 show the results of the questionnaire relating to deterioration of hips, radiological assessments, and adverse medical events.

The mean duration in months from the first IVMP infusion to the most recent hip $x$ ray was $56 \cdot 3$ months (range 8-116), only two patients being $x$ rayed within 12 months of their initial infusion. All

Table 4 Results of interviews and $x$ rays

\begin{tabular}{lcc}
\hline & \multicolumn{2}{c}{ Patients } \\
\cline { 2 - 3 } & IVMP & Control \\
\hline Dead & 5 & 11 \\
Uncontactable & 8 & 18 \\
Interviewed & 130 & 114 \\
Total number of hips $x$ rayed & 101 & 33 \\
Number reporting 'hip' deterioration & 40 & 38 \\
$\quad$ (Number $x$ rayed) & $(33)$ & $(33)$ \\
Hip osteonecrosis according to: & 1 & 1 \\
Both radiologists & 3 & 0 \\
One radiologist & & \\
\hline
\end{tabular}

Table 5 Adverse medical events

\begin{tabular}{lcc}
\hline & \multicolumn{2}{c}{ Patients } \\
\cline { 2 - 3 } & IVMP & Control \\
\hline Cardiovascular & 12 & 22 \\
Dermatological & 6 & 5 \\
Endocrine & 1 & 6 \\
Gastrointestinal & 12 & 13 \\
Genitourinary & 4 & 10 \\
Haematological & 2 & 0 \\
Musculoskeletal & 3 & 5 \\
Neurological & 4 & 2 \\
Special senses & 1 & 0 \\
Surgical & 4 & 4 \\
\hline
\end{tabular}

cases of definite or 'possible' osteonecrosis admitted? deterioration in their hips since the reference date $\vec{F}$ Failure to obtain hip $x$ rays was due to patienf refusal, non-attendance, or unavailability of the patient.

Both radiologists agreed a diagnosis of osteonec rosis of a hip in two patients, one in the IVMP and one in the control group. In three other patients treated with IVMP osteonecrosis was reported by only one. The reported medical events were very் diverse and categorised into the main system dis $\vec{\omega}$ eases (Table 5). Fifty six (39\%) of the 143 patients treated with IVMP reported various medical event after the reference date compared with $73(51 \%)$ of the 143 controls.

\section{Discussion}

There is gradual recognition that IVMP can be helpful in RA during the initiation of second line antirheumatic drug treatment ${ }^{23}$ and effective in? treating the more severe complications of the disease.

There are anecdotal reports of osteonecrosis of the hips in patients with RA treated with IVIIR even, in one case, after an infusion containing ofl lo $40 \mathrm{mg}$ methylprednisolone (unpublished comi munication). The association between osteonecrosis and corticosteroids in renal transplantation is welp documented. Susan et al noted an incidence ow avascular necrosis of the hip varying from 4 to $5 \%$ in 415 patients irrespective of the method of administration of glucocorticosteroid, the onse甲 occurring usually within 18 months. ${ }^{21}$ Haajanen et $a l$, who routinely $x$ rayed 546 renal transplan recipients, noted a similar incidence but found there was a significant correlation with the number of IV MP pulses which tended to be given in multiple infusions over relatively short periods, ${ }^{22}$ a regime $\vec{p}$. differing from that used in RA.

In this study there was one radiologically agree

Table 6 Clinical status of patients with definite or possible osteonecrosis

\begin{tabular}{|c|c|c|c|c|c|}
\hline & \multicolumn{2}{|l|}{ Definite } & \multicolumn{2}{|l|}{ Possible } & \multirow{3}{*}{$\begin{array}{l}5 \\
\text { IVMP }\end{array}$} \\
\hline & 1 & 2 & 3 & 4 & \\
\hline Group & Control & IVMP & IVMP & IVMP & \\
\hline Age (years) & 59 & 33 & 70 & 49 & 50 \\
\hline Sex & $\mathbf{M}$ & $\mathbf{F}$ & $\mathbf{F}$ & $\mathbf{F}$ & $\mathbf{M}$ \\
\hline Duration of disease (months) & 24 & 96 & 432 & 144 & 276 \\
\hline Severity & Mild & Severe & Mild & Severe & Severe \\
\hline Serology & + & + & + & + & + \\
\hline Erosions & + & + & + & + & + \\
\hline No of $1 \mathrm{~g}$ infusions & 0 & 2 & 2 & 11 & 2 \\
\hline
\end{tabular}

Patients 4 and 5 had received oral corticosteroids before but not at the time of IVMP treatment. Patient 4 had a right total hị replacement before IVMP treatment. 
case of definite osteonecrosis of the hip in each group; in addition there was disagreement over three further cases in the IVMP group but none in the controls. As there is one case of osteonecrosis in the control group, Fisher's exact test requires at least six cases of osteonecrosis in the IVMP group to establish a significant difference between them. The 'study power' is curtailed, however, by the number of patients available, but as the authors are not aware of a larger cohort of patients with RA treated with IVMP over a similar period this probably represents the upper limit of precision currently obtainable. The study, nevertheless, excludes a 'gross effect' by IVMP on the hips of patients with RA.

Table 6 shows the clinical status of the two patients with definite and the three with doubtful osteonecrosis.

Although the recording of concomitant drug treatment for all patients was considered impractical, the case notes of those with definite or doubtful osteonecrosis were studied to establish whether they had received corticosteroids. Two of the 'doubtful' group had received a short course of an oral preparation during the study period, but none had received an intra-articular injection into their hips. It is noteworthy that the control patient with definite osteonecrosis had not received any form of corticosteroid.

It is interesting that only five of the treated patients died compared with 11 deaths in the control group, but it would be unreasonable to claim that IVMP decreases mortality in RA. When grouped into systems the medical events show no gross differences although, contrary to experience with oral corticosteroid treatment, more cardiovascular events are reported in the control group. Overall, there is no significant difference between the two groups and, in particular, no excess of gastrointestinal disease, glucose intolerance, infections, or cardiac failure in the IVMP group-information of some clinical value.

\section{Conclusions}

This study indicates that when used in the treatment of RA an IVMP infusion of $1 \mathrm{~g}$ given either once only or after intervals of several months does not produce an increase in adverse medical events or a significant increase in the occurrence of osteonecrosis of the hips compared with the control group.

We wish to record our thanks to Upjohn Ltd, who provided generous computer access and to Sister Moon and staff of the radiology department for their help in organising appropriate $x$ rays.

\section{References}

1 Cathcart E S, Idelson B A, Steinberg M A, Couser W G. Beneficial effects of methylprednisolone 'pulse' therapy in diffuse proliferative lupus nephritis. Lancet 1976; i: 163-6.

2 Levinsky R J, Cameron J S, Soothill J F. Serum immune complexes and disease activity in lupus nephritis. Lancet 1977; i: 564-7.

3 Neild G H, Lee H A. Methylprednisolone pulse therapy in the treatment of polyarteritis nodosa. Postgrad Med J 1977; 53: 382-7.

4 Fan P T, Yu D T Y, Clements P J, Fowlston S, Eisman J, Bluestone R. Effect of corticosteroids on the humane immune response: comparison of one and three daily $1 \mathrm{gm}$ intravenous pulses of methylprednisolone. J Lab Clin Med 1978; 91: 625-34.

5 Liebling M R, Leib E, McLaughlin K, et al. Pulse methylprednisolone in rheumatoid arthritis. Ann Intern Med 1981; 94: 21-6.

6 Miller J J. Prolonged use of large intravenous steroid pulses in the rheumatic diseases of children. Pediatrics 1980; 65: 989-94.

7 Williams I A, Baylis E M, English J. High dose intravenous methylprednisolone (pulse therapy) in the treatment of rheumatoid disease. Scand J Rheumatol 1981; 10: 153-5.

8 Williams I A, Baylis E M, Shipley M E. A double blind placebo controlled trial of methylprednisolone pulse therapy in active rheumatoid disease. Lancet 1982; ii: 237-40.

9 Forster P J G, Grindulis K A, Neumann V, Hubball S. McConkey B. High-dose intravenous methylprednisolone in rheumatoid arthritis. Ann Rheum Dis 1982; 41: 444-6.

10 Bocanegra T S, Castañada M O, Espinoza L R, Vasey F B, Germain B F. Sudden death after methylprednisolone pulse therapy. Ann Intern Med 1981; 95: 122.

11 Moses R E, McCormick A, Nickey W, Fatal arrythmia after pulse methylprednisolone therapy. Ann Intern Med 1981; 95: 781-2.

12 Warren D J, Smith R S. High-dose prednisolone. Lancet 1983; i: $593-4$.

13 Alves L E, Rose E P. Complications of steroid therapy for rheumatoid arthritis. Ann Intern Med 1981; 94: 713.

14 Lake K B, Browne P M, Van Dyke J J, Ayers L. Fatal disseminated aspergillosis in an asthmatic patient treated with corticosteroids. Chest 1983; 83: 138-9.

15 Becq H, Dequeker J. Hypersensitivity reaction to pulse dose of methylprednisolone (Solumedrol); a case report. Acta Clin Belg 1983; 38: 262-4.

16 Garrett R, Paulus H. Complications of intravenous methylprednisolone pulse therapy in rheumatoid arthritis. Arthritis Rheum 1980; 23: 677.

17 Suchman A L, Condemi J J, Leddy J P. Seizure after pulse therapy with methylprednisolone. Arthritis Rheum 1983; 26: 117.

18 Oto A, Oktay A, Sözen T. Methylprednisolone and peritonitis. Ann Intern Med 1983; 99: 282.

19 Wollheim F A. Acute and long term complications of corticosteroid pulse therapy. Scand J Rheumatol 1985; 54 (suppl): 27-54.

20 Mussche M M, Ringoir S M G, Lameire N N. High intravenous doses of methyprednisolone for acute cadaveric renal allograft rejection. Nephron 1976; 16: 287-91.

21 Susan L P, Braun W E, Banowsky L H, Straffon R A, Bergfeld J A. Avascular necrosis following renal transplantation. Experience with 449 allografts with and without high dose steroid therapy. Urology 1978; 11: 225-9.

22 Haajanen J, Saarinen O, Laasonen L, Kuhlback B, Edgren J, Slatis P. Steroid treatment and aseptic necrosis of the femoral head in renal transplant recipients. Transplant Proc 1984; 16: 1316-8.

23 Neumann V, Hopkins R, Dixon J, Watkins A, Bird H, Wright $\mathrm{V}$. Combination therapy with pulsed methylprednisolone in rheumatoid arthritis. Ann Rheum Dis 1985; 44: 747-51. 